Wang, R. et al. (2013). Selenium functionalized carbon for high dispersion of platinumeruthenium nanoparticles and its effect on the electrocatalytic oxidation of methanol. Journal of Power Sources, 233: 326 - 330.

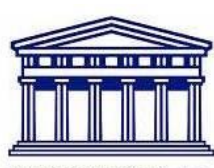

UNIVERSITY of the WESTERN CAPE

\title{
Selenium functionalized carbon for high dispersion of platinumeruthenium nanoparticles and its effect on the electrocatalytic oxidation of methanol
}

Rongfang Wang, Huahua Da, Hui Wang, Shan Ji and Zhongqun Tian

\begin{abstract}
Using selenium functionalized carbon as supports, platinumeruthenium nanoparticles were highly dispersed on the carbon surface, and showed improved electrochemical properties for methanol electrooxidation. The method provides a new route for functionalization of the carbon surface on which to disperse noble metal nanoparticles for application as electrocatalysts in fuel cells.
\end{abstract}

\section{Introduction}

Platinumeruthenium (PtRu) bimetallic electrocatalysts have been considered as promising electrocatalysts for methanol oxidation reaction (MOR) in direct methanol fuel cells (DMFCs) due to their high activities and CO tolerance [1]. PtRu catalysts are generally dispersed as nanoparticles (NPs) on a carbon support in order to obtain optimum catalyst utilization for methanol electrooxidation by increasing the dispersion of the nanosized catalysts. Therefore, highly distributed PtRu NPs with small size and narrow size distribution are ideal for high electrocatalytic activity owing to their large surface-to-volume ratio [2]. It is well known that the physicochemical properties of the support can greatly influence the dispersion and interaction between catalyst NPs with the support, and consequently their electrochemical behavior. From this perspective, some of the recent studies have employed new carbon materials, such as, carbon capsules [3], graphitic carbon nitride [4] and C60 [5] as supports to achieve a desired distribution of the PtRu NPs on the surface of the supports, and these catalysts exhibited improved performance for methanol oxidation. However, these new carbon materials do not yet meet the target for practical application because the complex synthesis methods are not suitable for industrial production. Another promising route is the use of chemical functional groups, such as carboxylate [6], 1,6hexamethylenediamine [7], 2- aminophenoxazin-3-one [8], and 3,4,9,10-perylene tetracarboxylic acid [9] to functionalize the surface properties of carbon materials to enhance the dispersion of PtRu NPs, thus increasing their utilization and electrocatalytic activity. In the last two decades, there has been increasing evidence to show that the electrochemical and physical properties of carbon materials are extremely sensitive to heteroatoms, such as $\mathrm{N}$ atoms, functionalizing the carbon surface or doping into the carbon 
structure [10e13]. Heteroatom functional groups introduced into carbon support appear to influence not only the active sites of the carbon support, which results in smaller catalyst particle size and increased catalyst particle dispersion, but also increases support/catalyst chemical binding (or "tethering"), which in turn results in enhanced stability of the catalysts. Furthermore, the metallic NPs electronic structure is modified, which enhances intrinsic catalytic activity [14]. In spite of these advantages, developing new heteroatom functionalities for modification of the carbon materials that provide well-dispersed noble metal NPs are still desirable.

Selenium, an element of the chalcogenide group and a semi-metal, has several advantages over the widely studied conventional heteroatom doping elements: 1 ) the electric conductivity of selenium facilitates electron transport during the electrochemical reactions [15]; 2) voltammetric studies show that selenium is stable in acid solution and shows a double layer region from -0.2 to $0.75 \mathrm{~V}$ (vs. SHE), which is wider than that of $\mathrm{Pt}$ (-0.4 to $0.7 \mathrm{~V}$ (vs. SHE)) [16]; 3) the catalyst may show better stability at high temperature due to the anchor effect of selenium atoms [17]; 4) Selenium can become metallic when bound to metals resulting in exceptional chemical stability in acidic media, even at high positive potential [18]. Thus, the synthesis of selenium functionalized carbon and a study of their support effect are of great interest.

Herein, by selecting carbon black Vulcan XC-72 as the support, because it is a commercial and widely used support in electrocatalysis, an alternative strategy for dispersing PtRu alloy NPs on carbon is reported. In detail, triphenyl phosphine selenide $\left(\mathrm{PPh}_{3} \mathrm{Se}\right)$ resulting from triphenyl phosphine $\left(\mathrm{PPh}_{3}\right)$ and selenium (Se) was non-covalently coupled to the surface of the conventional oxidised carbon (as shown in Fig. 1). The resulting $\mathrm{PPh}_{3} \mathrm{Se}$ and carboxylate modified carbon were heat treated to remove $\mathrm{PPh}_{3}$, Thus the surface of carbon can be modified by non-covalent adsorption of selenium. Using of selenium functionalized carbon (SeeC) as supports, highly dispersed PtRu NPs with narrow size distribution on carbon were synthesized and showed higher electrocatalytic activity and stability toward methanol electrooxidation than that supported on oxidized carbon (C).

\section{Experimental}

\subsection{Synthesis}

The procedure for selenium functionalization of carbon was prepared by a modified organic colloid method [19]. Carbon black (Vulcan XC-72R, Carbot Corp.) was pretreated by washing with acetone, oxidized with $2 \mathrm{~mol} \mathrm{~mL}^{-1} \mathrm{HNO}_{3}$ and $30 \% \mathrm{H}_{2} \mathrm{O}_{2}$, then washed with ultrapure water and dried overnight at $80{ }^{\circ} \mathrm{C}$, the pretreated carbon black $(\mathrm{C})$ was obtained. $0.185 \mathrm{~g}$ of triphenyl phosphine were dissolved in $30 \mathrm{~mL}$ of tetrahydrofuran in a flask whilst stirring for $20 \mathrm{~min}$, and $0.0504 \mathrm{~g}$ of elemental selenium was added and dissolved with stirring, then $1.002 \mathrm{~g}$ of the pretreated $\mathrm{C}$ were dispersed by ultrasonically into the solvent. The above solvent was transferred into a rotary dryer, and tetrahydrofuran was evaporated at $40{ }^{\circ} \mathrm{C}$. The mixture was dried in air at $60^{\circ} \mathrm{C}$, and thermally treated in a tubular furnace

\section{http://repository.uwc.ac.za}


under a $\mathrm{N}_{2}$ atmosphere at $500{ }^{\mathrm{O}} \mathrm{C}$ for $2 \mathrm{~h}$. The selenium functionalized carbon (SeeC) sample was obtained.

The detailed preparation process of the catalyst according to the literature [20] could be described as follows: $0.50 \mathrm{~mL}$ of $\mathrm{RuCl}_{3}\left(20 \mathrm{mg} \mathrm{mL}^{-1}\right)$ solution and $0.97 \mathrm{~mL}$ of $\mathrm{H}_{2} \mathrm{PtCl} 6$ (20 mg mL ${ }^{-1}$ ) solution were dissolved to a $100 \mathrm{~mL}$ flask with $30 \mathrm{~mL}$ ethylene glycol (EG) under stirring conditions. $500 \mathrm{mg}$ of sodium citrate were dissolved the above solution, then $156 \mathrm{mg}$ of sodium formate were added into the solution. $\mathrm{pH}$ of the system was adjusted to w11 by adding $5 \mathrm{wt} \% \mathrm{KOH} /$ ethylene glycol solution dropwise with vigorous stirring. $100 \mathrm{mg}$ of SeeC was added into the flask. The mixture was sonicated for $20 \mathrm{~min}$ and stirred $20 \mathrm{~min}$ to disperse the SeeC. The resulting solution was heated at $160{ }^{\circ} \mathrm{C}$ for $8 \mathrm{~h}$. After filtering and washing with ultrapure water, the sample (denoted as $\mathrm{PtRu} / \mathrm{SeeC}$ ) was obtained by dried overnight in air at $60{ }^{\circ} \mathrm{C}$ for $24 \mathrm{~h}$. For a comparison, the PtRu nanoparticles supported on the pretreated carbon black $(\mathrm{PtRu} / \mathrm{C})$ electrocatalysts were also prepared by using the same procedure.

\subsection{Characterization}

The obtained materials' structure was characterized by recording their X-ray diffraction (XRD) patterns on a Shimadzu XD-3A (Japan), using filtered $\mathrm{Cu}$ Ka radiation (40 kV, $40 \mathrm{~mA}$ ). Xray photoelectron spectroscopy (XPS) was obtained by a PHI-5702 multifunctional X-ray photoelectron spectrometer (American). The average chemical compositions of $\mathrm{PtRu} / \mathrm{SeeC}$ and $\mathrm{PtRu} / \mathrm{C}$ catalyst were determined using an IRIS advantage inductively coupled plasma atomic emission spectroscopy (ICP-AES) system (Thermo, America) and EDX coupled TEM.

\subsection{Electrochemical measurements}

The electrochemical measurements of catalysts were performed using a CHI650 electrochemical work station. A conventional three-electrode electrochemical cell was used for the measurements, including a platinum wire as the counter electrode, an $\mathrm{Ag} / \mathrm{AgCl}$ ( $3 \mathrm{M}$ $\mathrm{KCl})$ electrode as the reference electrode, and a modified glass carbon electrode $(5 \mathrm{~mm}$ in diameter, $0.196 \mathrm{~cm}^{2}$ ) as the working electrode was prepared as follows: $5 \mathrm{mg}$ of catalyst was dispersed ultrasonically in $1 \mathrm{~mL}$ of Nafion/ethanol (0.25 wt\% Nafion). About $8 \mathrm{~mL}$ of the dispersion was transferred onto the glassy carbon (GC) disc using a pipette, and then dried in the air to the preparation of the catalyst layer on it. Before each measurement, the solution was purged with high-purity $\mathrm{N}_{2}$ gas for at least 30 min to ensure the gas saturated. The recorded cyclic voltammograms are the $25^{\text {th }}$ circles.

\section{Results and discussion}

Raman spectra of SeeC and C are shown in Fig. 2a peak at $1310 \mathrm{~cm}^{-1}$ can be assigned to the $\mathrm{A}_{1}$ g disordered graphite structure (i.e., the $\mathrm{D}$ band), and the peak at

w158 $\mathrm{cm}^{-1}$ assigned to the $E_{2}$ g structural mode of graphite (i.e., the $\mathrm{G}$ band). Comparison of the Raman spectra of SeeC and C shows that D band and G band do not significantly change in both width and shape after functionalization. The extent of the defects in graphite

\section{http://repository.uwc.ac.za}


materials can be quantified by the intensity ratio of the $\mathrm{D}$ to $\mathrm{G}$ bands (i.e., $I_{\mathrm{D}} / I_{\mathrm{G}}$ ). The $I_{\mathrm{D}} / I_{\mathrm{G}}$ ratio of SeeC (1.13) is smaller than that of $C$ (1.18), suggesting that the $s p^{2}$ carbon network of graphene was not damaged by functionalization [21e23], so, the carbon support appears to retain its original structure.

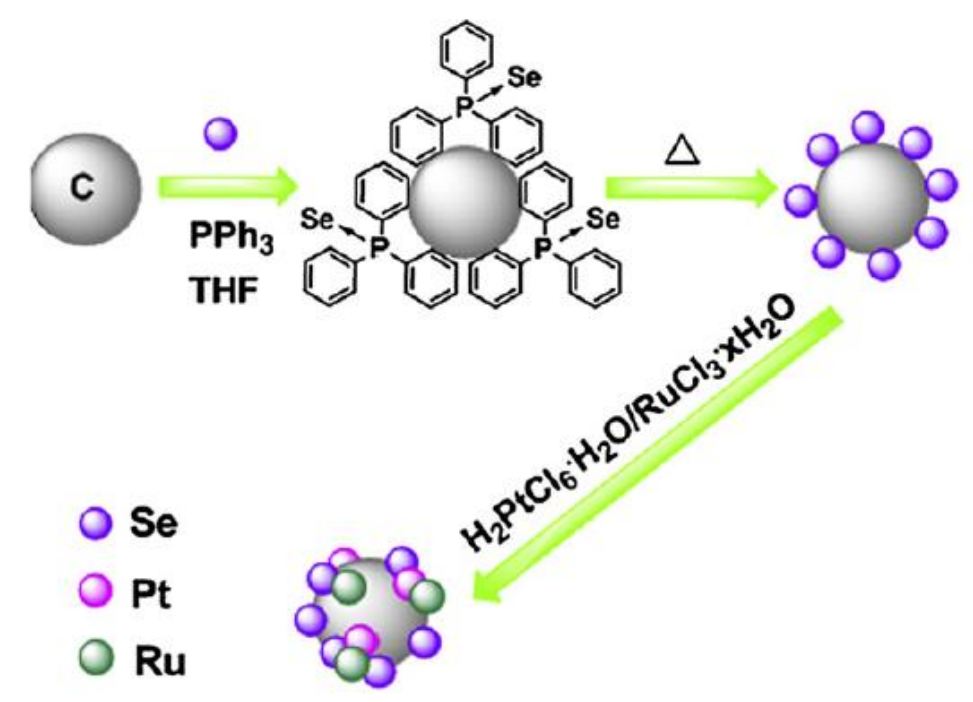

Fig. 1. Schematic diagram for Se-functionalized carbon and dispersion of PtRu nanoparticles.

The slight decrease of the $I_{\mathrm{D}} / I_{\mathrm{G}}$ ratio after selenium functionalization of the carbon may be attributed to the fact that the original defect sites on the carbon surface are covered by the selenium atoms, as reported in literature for the 3,4,9,10-perylene tetracarboxylic acidfunctionalized CNTs [9].

The FT-IR spectra of $\mathrm{C}$ and SeeC are plotted in Fig. 2b. In the two curves, OeH band of OH group located at $\mathrm{w} 3440 \mathrm{~cm}^{-1}$ and the C]O band of carboxylic acid groups at $\mathrm{w} 1640 \mathrm{~cm}^{-1}$ are presented. These groups were introduced upon treatment with $\mathrm{H}_{2} \mathrm{O}_{2}$ and $\mathrm{HNO}_{3}$ [24]. The antisymmetric CeSe stretching at $605 \mathrm{~cm}^{-1}$, the symmetric Ce Se stretching at $507 \mathrm{~cm}^{-1}$ and the CeSe bending mode at 462 and $436 \mathrm{~cm}^{-1}$ cannot be clearly assigned in the FT-IR spectrum of SeeC [25]. The results indicate possible non-covalent bonding of the selenium atoms. No characteristic diffraction peaks of $\mathrm{PPh}_{3}$ are observed, implying that $\mathrm{PPh}_{3}$ was removed by heat treatment.

The morphology of SeeC was characterized by transmission electron microscopy (TEM). Fig. 2c shows that SeeC particles are in powder form, which is consistent with other reports of Vulcan carbon morphology [26]. Further, it can be clearly observed that no heterogeneous NPs exist on the carbon surface, which was also confirmed from the high resolution transmission electron microscopy (HRTEM, the insert in Fig. 2b). Based on these analyses, it is conceivable that selenium atoms are uniformly attached onto the carbon surface by non-covalent adsorption. 
Fig. 3a and b shows the TEM images of the PtRu/SeeC and PtRu/ C samples. As shown in Fig. 3a, the SeeC is successfully decorated with many well-dispersed PtRu NPs. No evidence was observed of larger agglomerated particles on the SeeC surface. However, PtRu NPs aggregation clearly presents on the $\mathrm{C}$ surface. The distribution of PtRu NPs in the PtRu/SeeC catalyst shown as inset in Fig. $3 \mathrm{a}$ and $\mathrm{b}$ is narrow compared to that of $\mathrm{PtRu} / \mathrm{C}$ catalyst. This is due to the presence a large number of Se atoms on the $\mathrm{C}$ surface with uniform distribution that serve as the functional groups for the immobilization of PtRu NPs, leading to high dispersion and narrow distribution. EDX study of the PtRu/SeeC catalysts shown in Fig. $3 \mathrm{c}$ indicates the presence of $\mathrm{Pt}, \mathrm{Ru}, \mathrm{Se}, \mathrm{C}$ and $\mathrm{O}$, while that of the $\mathrm{PtRu} / \mathrm{C}$ catalysts in Fig. $3 \mathrm{~d}$ indicates the presence of $\mathrm{Pt}, \mathrm{Ru}, \mathrm{C}$ and $\mathrm{O}$. The loading mass of PtRu and Se of the $\mathrm{PtRu} / \mathrm{SeeC}$ catalysts determined by ICP is $9.86 \%$ and $3.83 \%$, respectively, with $1: 1 \mathrm{of} \mathrm{Pt} / \mathrm{Ru}$ atom ratio. The loading mass of $\mathrm{PtRu}$ of the $\mathrm{PtRu} / \mathrm{C}$ catalysts is $9.92 \%$ with $1: 1 \mathrm{of} \mathrm{Pt} / \mathrm{Ru}$ atom ratio, suggesting $\mathrm{Pt}$ and $\mathrm{Ru}$ are completely reduced. XRD was used to analyze the crystalline structure of the $\mathrm{PtRu} / \mathrm{SeeC}$ and $\mathrm{PtRu} / \mathrm{C}$ samples. No peaks from elemental Se were detected in the PtRu/SeeC sample (see Fig. 3e); thus, elemental Se appears to be homogeneously dispersed on the carbon particles [27], which is consistent with the TEM result. Before and after Se functionalization carbon, the crystalline structure of PtRu is not altered by the coexisting Se atoms. However, the electronic structure of Pt in the PtRu/SeeC sample clearly changes as shown by XPS (Fig. 3f). The Pt binding energies of the PtRu/SeeC and PtRu/C samples shift to the higher energy as compared to those of Pt/C, which can be attributed to the stronger metal-to-support interaction and a smaller particle size [11,28]. The Pt binding energies of the PtRu/SeeC shift to the lower energy by ca. $0.5 \mathrm{eV}$ in related to those of $\mathrm{PtRu} / \mathrm{C}$ samples, which is attributed that electron transfer occurs from Se to Pt (electronegativity: $\mathrm{Pt}=2.28, \mathrm{Se}=2.40$ ).

Fig. 4a shows the cyclic voltammograms (CVs) of the PtRu/See $\mathrm{C}$ and $\mathrm{PtRu} / \mathrm{C}$ catalysts measured in a nitrogen-saturated $0.5 \mathrm{M} \mathrm{H}_{2} \mathrm{SO}_{4}$ solution. The two catalysts exhibit hydrogen adsorption/ desorption peaks in the potential range from -0.20 to $0.10 \mathrm{~V}$, and oxide formation/stripping wave peaks in the potential range from ca. $0.30 e 1.0 \mathrm{~V}$. As can be seen from Fig. 4a, the onset potentials for the oxide reduction in the negative-going sweep are apparently shifted to more positive potential for the $\mathrm{PtRu} / \mathrm{SeeC}$ catalysts as compared to PtRu/C. This shift indicates that the PtRu structure inhibits chemisorption the oxygenated species such as $\mathrm{OH}_{\mathrm{ad}}$ chemisorb on the active sites of the $\mathrm{PtRu} / \mathrm{SeeC}$ catalysts at high potential due to the change of the electronic structure induced by the presence of Se. 

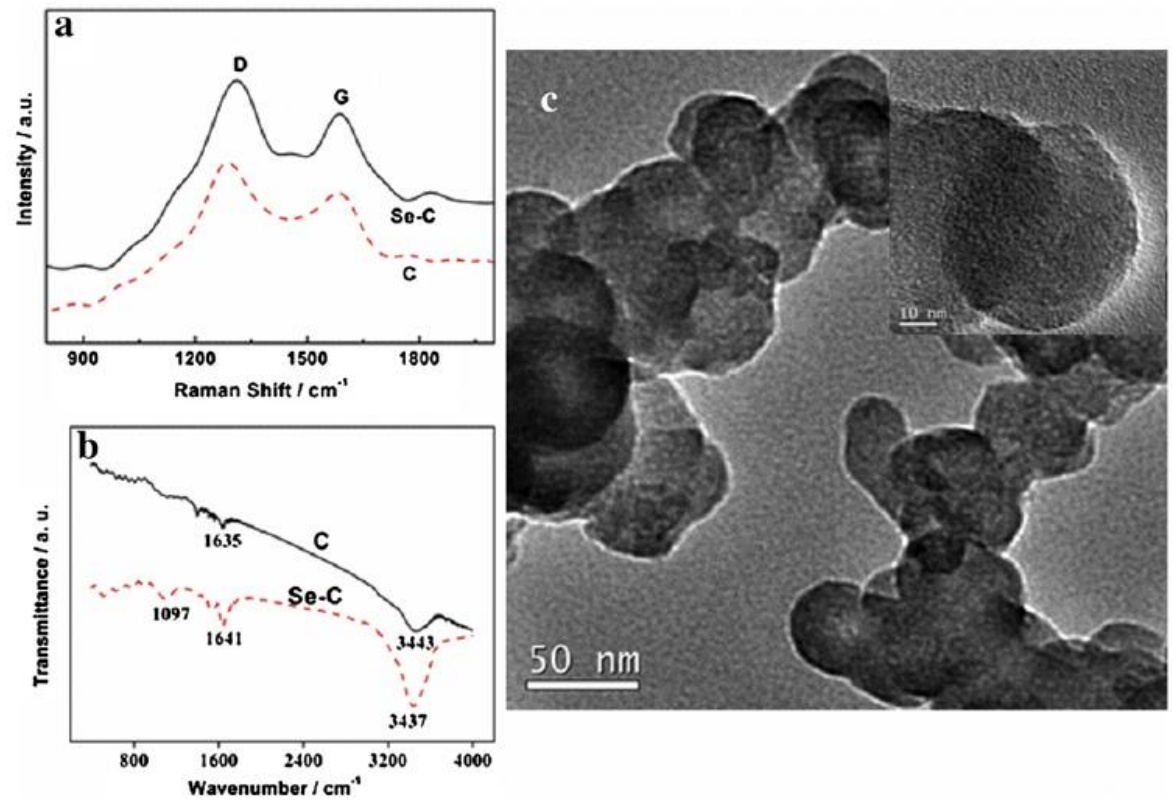

Fig. 2. Raman spectra (a) and FT-IR (b) of Se-C and C; The TEM image of Se-C (c), Inset of a HRTEM image of Se-C.
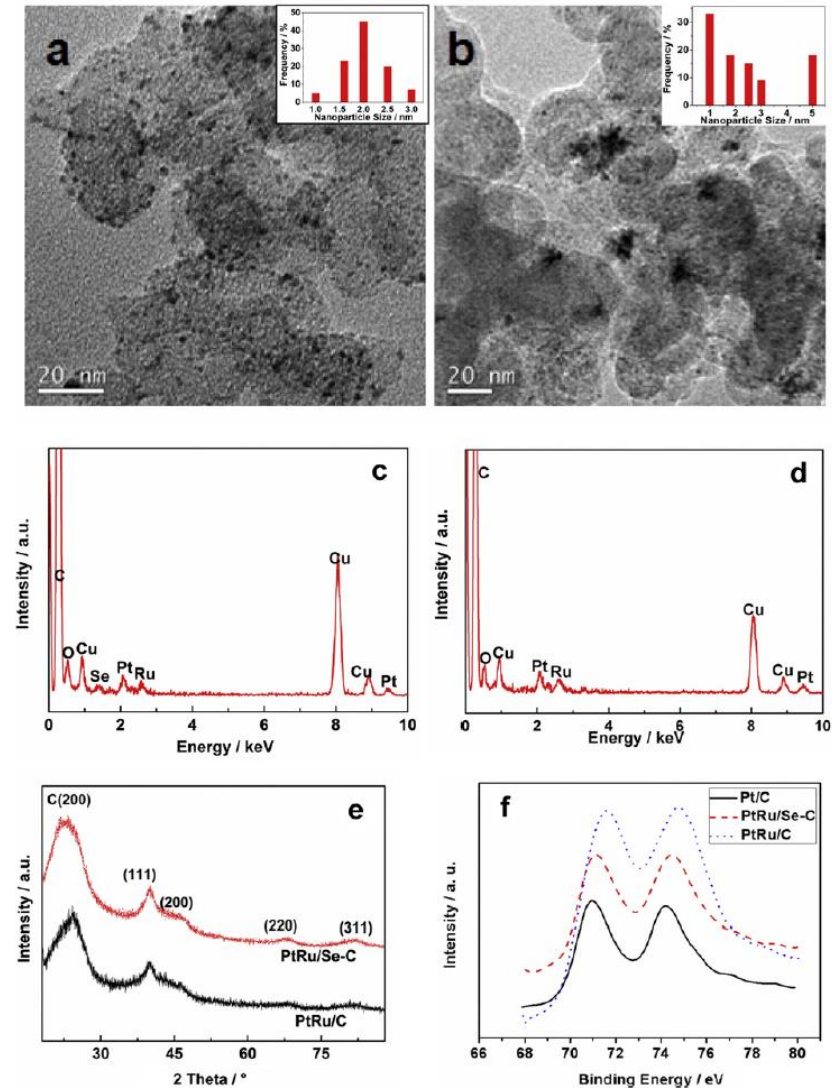

Fig. 3. (a) TEM image of the as-prepared PtRu/Se-C and (b) PtRu/C; Inserts in a and b: (top right corner) particle size distribution histograms of catalysts; (c) EDX of the as-prepared $\mathrm{PtRu} / \mathrm{Se}-\mathrm{C}$ and (d) PtRu/C; (e) XRD patterns of the PtRu/Se-C and PtRu/C samples; (f) XPS spectra for Pt $4 \mathrm{f}$ of Pt/C, PtRu/Se-C and PtRu/C.

From the hydrogen desorption peak areas, the electrochemical surface area (ECSA) of the $\mathrm{PtRu} / \mathrm{SeeC}$ and $\mathrm{PtRu} / \mathrm{C}$ catalysts were calculated from the $\mathrm{CV}$ curves according to literature methods [29]. The ECSA value of the PtRu/SeeC and PtRu/C catalysts is 84.6

\section{http://repository.uwc.ac.za}


and $69.5 \mathrm{~m}^{2} \mathrm{~g}^{-1}$ of $\mathrm{Pt}$, respectively. The higher ECSA of PtRu/SeeC catalyst compared to that of $\mathrm{PtRu} / \mathrm{C}$ catalysts is due to much better dispersion of PtRu nanoparticles on the SeeC support.

Fig. 4b shows the CVs recorded for the PtRu/SeeC and PtRu/C catalysts in $0.5 \mathrm{M}$ $\mathrm{H}_{2} \mathrm{SO}_{4}$ solution with $0.5 \mathrm{M} \mathrm{CH}_{3} \mathrm{OH}$ in the potential range -0.2 to 1.0 V. Methanol oxidation occurs at a relatively lower potential and the current peak normalized to the ECSA is significantly higher for the PtRu/SeeC catalyst compared to that of the $\mathrm{PtRu} / \mathrm{C}$ catalyst. The negative shift, ca. $52 \mathrm{mV}$, of the onset potential for the $\mathrm{PtRu} / \mathrm{SeeC}$ catalyst (0.14 V vs. Ag/AgCl) compared with $0.19 \mathrm{~V}$ of the $\mathrm{PtRu} / \mathrm{C}$ catalyst indicates good electrocatalytic activity of the PtRu/ SeeC catalyst. It is also noted that the forward peak potential of methanol oxidation on the PtRu/SeeC catalyst is clearly more negative than that on $\mathrm{PtRu} / \mathrm{C}$ catalysts. A specific activity for the methanol oxidation reaction for the $\mathrm{PtRu} / \mathrm{SeeC}$ catalyst, $0.58 \mathrm{~mA} \mathrm{~cm}{ }^{-2}$, is exhibited, while that of the $\mathrm{PtRu} / \mathrm{C}$ catalyst is less at $0.44 \mathrm{~mA} \mathrm{~cm}^{-2}$. The higher electrocatalytic activity of the $\mathrm{PtRu} / \mathrm{SeeC}$ catalyst compared with the PtRu/C catalyst could be due to better dispersion.

Further, to compare the possible poisoning of the $\mathrm{PtRu} / \mathrm{SeeC}$ and $\mathrm{PtRu} / \mathrm{C}$ catalysts under short time continuous operation toward the methanol oxidation reaction, chronoamperometry tests, shown in Fig. $4 \mathrm{c}$ in $0.5 \mathrm{M} \mathrm{H}_{2} \mathrm{SO}_{4}$ solution containing methanol for $1000 \mathrm{~s}$, were carried at a constant potential of $0.6 \mathrm{~V}$ vs. $\mathrm{Ag} / \mathrm{AgCl}$. In the initial time period the potentiostatic current density decreases rapidly for all the PtRu catalysts, which could be due to the formation intermediate species, such as $\mathrm{CO}_{\mathrm{ads}}$, $\mathrm{CH}_{3} \mathrm{OH}_{\mathrm{ads}}$, and $\mathrm{CHO}$ ads, during the methanol oxidation reaction [30]. At longer time periods although the current gradually decays for both catalysts, the PtRu/ SeeC catalysts maintain a higher current density than the PtRu/C catalyst throughout all ranges up to $1000 \mathrm{~s}$. The much higher tolerance of the PtRu/SeeC catalyst can be attributed to the change of electronic structure induced by the presence of Se.

First and second CVs during the stripping of a $\mathrm{CO}$ monolayer for $\mathrm{PtRu} / \mathrm{SeeC}$ and $\mathrm{PtRu} / \mathrm{C}$ catalysts are given in Fig. 4d. The adsorption time of $\mathrm{CO}$ was set to 5 min since a further increase in the adsorption time did not change the voltammograms [31]. 

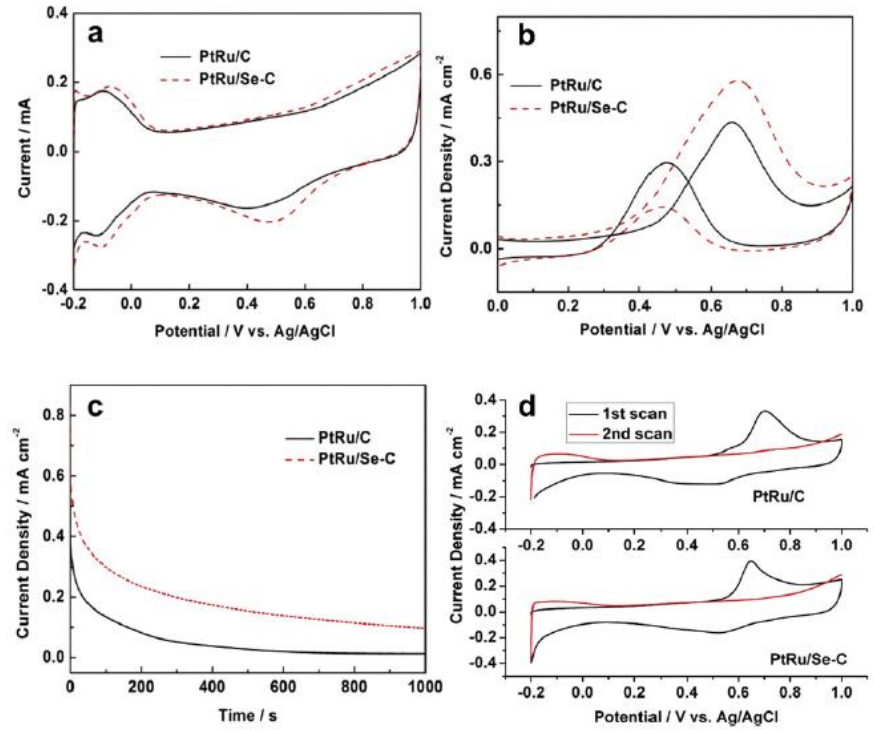

Fig. 4. Cyclic voltammograms of PtRu/Se-C and PtRu/C catalysts in (a) nitrogen saturated $0.5 \mathrm{M} \mathrm{H}_{2} \mathrm{SO}_{4}$ : (b) nitrogen saturated $0.5 \mathrm{M} \mathrm{H}_{2} \mathrm{SO}_{4}+0.5 \mathrm{M} \mathrm{CH}_{3} \mathrm{OH}_{\text {at }}$ a scan rate of $50 \mathrm{mV} \mathrm{s}^{-1}$; and (c) chronoamperometry tests of methanol oxidation of PtRu/Se-C and PtRu/C catalysts in $0.5 \mathrm{M} \mathrm{CH} \mathrm{CH}_{3} \mathrm{OH}$ and $0.5 \mathrm{M} \mathrm{H}_{2} \mathrm{SO}_{4}$ solution; and (d) CO stripping curves of $\mathrm{PtRu} / \mathrm{Se}-\mathrm{C}$ and $\mathrm{PtRu} / \mathrm{C}$ catalysts in $0.5 \mathrm{M} \mathrm{H}_{2} \mathrm{SO}_{4}$ solution at a scan rate of $50 \mathrm{mV} \mathrm{s}^{-1}$.

A clean surface is recovered in the second cycle coinciding with the voltammogram described in the literature. For $\mathrm{PtRu} / \mathrm{C}$, the $\mathrm{CO}$ oxidation peak at $0.7 \mathrm{O} \mathrm{V}$ attains the $\mathrm{CO}$ oxidation peak of $\mathrm{PtRu} / \mathrm{SeeC}(0.65 \mathrm{~V})$ shift to lower potential by ca. $50 \mathrm{mV}$. This result implies the $\mathrm{PtRu} / \mathrm{Se}-\mathrm{C}$ catalyst with the better $\mathrm{CO}$ tolerance than the $\mathrm{PtRu} / \mathrm{C}$ catalyst, which could be attributed to the change of the Pt electronic structure induced by the presence of Se.

\section{Conclusions}

In summary, a new catalyst support, surface-selenium-enriched carbon, for the synthesis of noble metal catalysts, was successfully prepared by functionalized Vulcan carbon with non-covalently bonded Se atoms. PtRu NPs supported on the SeeC have better dispersion and higher electrochemical surface area than that on $\mathrm{C}$ without Se functionalization. Most importantly, the as-prepared PtRu/SeeC catalyst shows much better electrocatalytic activity toward methanol electrooxidation. The method reported here possesses a high potential for the fabrication of heteroatom functionalized carbon as a support for noble metal NPs in fuel cells.

\section{Acknowledgments}

This work was financially supported by the NSFC (21163018) and NSFPSC (20110490847 and 2012T50554). 


\section{References}

[1] R.J.K. Wiltshire, C.R. King, A. Rose, P.P. Wells, H. Davies, M.P. Hogarth,

D. Thompsett, Brian Theobald, F.W. Mosselmans, M. Roberts, A.E. Russell, Phys.

Chem. Chem. Phys. 11 (2009) 2305.

[2] R. Ahmadi, M.K. Amini, Int. J. Hydrogen Energy 36 (2011) 7275.

[3] G.S. Chai, S.B. Yoon, J.H. Kim, J.S. .Yu, Chem. Commun. 23 (2004) 2766.

[4] M. Kim, S. Hwang, J.S. Yu, J. Mater. Chem. 17 (2007) 1656.

[5] G. Lee, J.H. Shim, H. Kang, K.M. Nam, H. Song, J.T. Park, Chem. Commun. 28 (2009) 5036.

[6] P. Hernández-Fernández, R. Nuño, E. Fatás, J.L.G. Fierro, P. Ocón, Int. J. Hydrogen Energy 36 (2001) 8267.

[7] K. Kardimi, T. Tsoufis, A. Tomou, B.J. Kooi, M.I. Prodromidis, D. Gournis, Int. J. Hydrogen Energy 37 (2012) 1243.

[8] Y. Zhao, X. Yang, J. Tian, Electrochim. Acta 54 (2009) 7114.

[9] B. Wu, D. Hu, Y. Kuang, Y. Yu, X. Zhang, J. Chen, Chem. Commun. 47 (2011) 5253 .

[10] A. Stein, Z. Wang, M.A. Fierke, Adv. Mater. 21 (2009) 265.

[11] G. Wu, R. Swaidan, D. Li, N. Li, Electrochim. Acta 53 (2008) 7622.

[12] R. Chetty, S. Kundu, W. Xia, M. Bron, W. Schuhmann, V. Chirila, W. Brandl, T. Reinecke, M. Muhler, Electrochim. Acta 54 (2009) 4208.

[13] Z. Liu, F. Su, X. Zhang, S.W. Tay, ACS Appl. Mater. Interfaces 3 (2011) 3824. [14] Y. Zhou, K. Neyerlin, T.S. Olson, S. Pylypenko, J. Bult, H.N. Dinh, T. Gennett, Z. Shao, R. O’Hayre, Energy Environ. Sci. 3 (2010) 1437.

[15] A. Abouimrane, D. Dambournet, K.W. Chapman, P.J. Chupas, W. Weng, K. Amine, J. Am. Chem. Soc. 134 (2012) 4505.

[16] K.A. Kurak, A.B. Anderson, J. Electrochem. Soc. 157 (2010) B173. [17] Z. Wei, H. Guo, Z. Tang, J. Power Sources 62 (1996) 233.

[18] P.K. Babu, A. Lewera, J.H. Chung, R. Hunger, W. Jaegermann, N. AlonsoVante, A. Wieckowski, E. Oldfield, J. Am. Chem. Soc. 129 (2007) 15140.

[19] R.F. Wang, S.J. Liao, H.Y. Liu, H. Meng, J. Power Sources 171 (2007) 471. [20] H. Li, D. Kang, H. Wang, R. Wang, Int. J. Electrochem. Sci. 6 (2011) 1058.

[21] V. Georgakilas, A. Bourlinos, D. Gournis, T. Tsoufis, C. Trapalis, A. MateoAlonso, M. Prato, J. Am. Chem. Soc. 130 (2008) 8733.

[22] Y.J. Chen, G. Xiao, T.S. Wang, Q.Y. Ouyang, L.H. Qi, Y. Ma, P. Gao, C.L. Zhu, M.S. Cao, H.B. Jin, J. Phys. Chem. C 115 (2011) 13603.

[23] C.S. Lee, S.E. Baker, M.S. Marcus, W. Yang, M.A. Eriksson, R.J. Hamers, Nano Lett. 4 (2004) 1713.

[24] S. Kim, S.J. Park, J. Power Sources 159 (2006) 42.

[25] F. Cataldo, Polyhedron 19 (2000) 681.

[26] S.M.S. Kumar, J.S. Herrero, S. Irusta, K. Scott, J. Electroanal. Chem. 647 (2010) 211. [27] J. Inukai, D. Cao, A. Wieckowski, K.C. Chang, A. Menzel, V. Komanicky, H. You, J. Phys. Chem. C 111 (2007) 16889.

[28] J. Prabhuram, T.S. Zhao, Z.X. Liang, R. Chen, Electrochim. Acta 52 (2007) 2649 e 2656. 
[29] H. Wang, R. Wang, H. Li, Q. Wang, J. Kang, Z. Lei, Int. J. Hydrogen Energy 36 (2011) 839.

[30] J. Prabhuram, T.S. Zhao, Z.K. Tang, R. Chen, Z.X. Liang, J. Phys. Chem. B 110 (2006) 5245.

[31] T.J. Schmidt, M. Noeske, H.A. Gasteiger, R.J. Behm, Langmuir 13 (1997) 2592. 